\title{
Atributos Relevantes de Destinos Turísticos na Percepção de Internautas Brasileiros
}

\author{
The Perception of Brazilian's Internet Users about Relevant Attributes of Tourism \\ Destination Areas
}

Iomara Scandelari Lemos ${ }^{1}$

José Roberto Frega ${ }^{2}$

Alceu Souza ${ }^{3}$

\section{Resumo}

Este artigo objetiva identificar, na percepção do turista brasileiro, a estrutura subjacente da importância de atributos que caracterizam os destinos turísticos. Trata-se de uma pesquisa do tipo survey disponibilizada em website e respondida por 471 internautas brasileiros. Utilizaram-se procedimentos estatísticos de análise fatorial; validade de construto; construção de escalas e análise fatorial confirmatória com modelagem de equações estruturais. Concluise que, tomados isoladamente, os atributos considerados mais relevantes foram: sensação de segurança; qualidade do aspecto visual do destino; sensação de não estar sendo explorado e facilidade de acesso ao destino turístico, totalizando 70,5\% das respostas. Contudo, analisados em conjunto, três fatores respondem por $62,2 \%$ da variância explicada.

Palavras-chave: análise fatorial; modelagem de equação estrutural; atributos relevantes de turismo.

\footnotetext{
${ }^{1}$ Doutora em Administração (PUCPR), Mestre em Administração (PUCPR), Mestre em Gestão Pública do Turismo (UIA/Espanha), Especialista em Gestão Técnica do Meio Urbano (PUCPR; UTC/França), Graduada em Turismo (UFPR). Consultora em turismo da Leliz Consultoria Ltda. e professora colaboradora na Univeb. Email: iomara.lemos@gmail.com.

2 Doutor em Administração (PUCPR), Mestre em Administração (PUCPR), Especialista em Tecnologia da Informação e Comunicação (FAE-PR), Graduado em Engenharia Eletrônica (UFRJ). Analista de Sistemas no Paranácidade e professor da Faculdade Paranaense (FAPAR). E-mail: jose.frega@gmail.com.

${ }^{3}$ Doutor em Administração de Empresas (FGV-SP), Mestre em Engenharia de Produção (UFSC), Mestre em Systems Design (University of Waterloo/Canadá), Graduado em Economia (UFPR). Professor adjunto PUCPR e Co-autor de livros didáticos (Gestão de Custos, Decisões Financeiras e Análise de Investimentos, Projetos Empresariais e Públicos e Matemática Financeira) publicados pela Editora Atlas e de diversos artigos na área de gestão estratégica de custos. E-mail: alceu.souza@pucpr.br.
} 


\section{Abstract}

This article aims to identify, in the perception of Brazilian tourists, the subjacent structure of the importance of attributes that characterize the tourist places destinations. This research is a survey available on website and answered by 471 Brazilians internet users. It used statistical procedures such as factorial analysis, construct reliability, construction of scales and structural equation modeling for confirmatory factorial analysis. It was concluded that, taken alone, the attributes considered most important were: sensation of visiting a safety place, visual aspect quality of the tourism destination areas, sensation of not being exploited and facilities concerned to the tourism destination areas. These totalized $70.5 \%$ of responses. However, taken together, three factors account for $62.2 \%$ of variance explained.

Keywords: factorial analysis; structural equation modeling; tourism's relevant attributes.

\section{Introdução}

A escolha de um destino turístico raramente deve-se à casualidade. Mas o que leva um turista a viajar para determinado destino? A hipótese mais plausível é que existam fatores que levam o turista a determinado destino e não a outros, ou seja, há elementos que influenciam essa escolha. Dentre estes elementos, aqueles que se denominam como atrativos turísticos apresentam o principal fator de motivação da escolha. Ao verificar que a atividade turística só se mantém quando os destinos turísticos apresentam um grau de atratividade para os turistas, pode-se considerar que um objetivo geral dos destinos seja que haja percepção dos turistas quanto a sua atratividade. Assim, é função dos gestores de destinos turísticos assegurarem que essas atratividades sejam percebidas pelos turistas.

Há atrativos turísticos que são peculiares e específicos de determinados destinos turísticos como os atrativos naturais, culturais e eventos da localidade. Também há elementos de aspectos gerais existentes na maior parte dos destinos turísticos, embora com alguma variação, como segurança, conforto, facilidades de acesso, infraestrutura mínima, etc. Ambos requerem estratégias diferenciadas de atuação dos gestores desses destinos. Assim sendo, o foco desta pesquisa está na percepção, do ponto de vista do turista brasileiro, de como os elementos de aspectos gerais influenciam a decisão da escolha de determinado destino turístico. Espera-se que o resultado sistematizado desta pesquisa possa ser utilizado pelos gestores de destinos turísticos. 
Para realizar a pesquisa partiu-se de onze características principais (sendo dez escolhidas junto a especialistas - sendo estas existentes na maior parte dos destinos turísticos - e uma advinda do pré-teste) e da hipótese de que as características reveladas como importantes aos turistas apresentam diferentes graus entre os diversos tipos de respondentes, que representam segmentos variados na demanda.

E utilizou-se de metodologia quantitativa, com aplicação de um questionário validado em préteste e disponibilizado em website. Para análise da estrutura subjacente aos atributos que caracterizam os destinos turísticos na percepção do turista brasileiro quanto à importância destes elementos nos destinos turísticos, usaram-se ferramentas estatísticas como análise de componentes principais, análise fatorial, confiabilidade, validade de constructo, construção de escalas e equações estruturais. O instrumento respondido por 471 internautas de diversos Estados brasileiros, totalizando 469 respostas válidas.

\section{Fundamentação Teórica}

Para Dias (2005, p.75) “uma destinação turística pode ser considerada uma localidade, uma região ou um país que recebe visitantes que para lá se dirigem para passar um período relativamente curto". Segundo a OMT (2005, p.10, tradução dos autores), destino turístico é definido como "um espaço físico". Ou seja, o destino turístico é o espaço determinado que vai receber os visitantes. São considerados destinos turísticos as localidades e regiões que apresentam produtos, serviços e atrativos turísticos (oferta turística) capazes de atraírem turistas.

\subsection{Oferta turística}

Boullón (1985) e Beni (2000) reconhecem a existência de diversos fatores de atração para caracterizar a oferta de certo destino turístico. Para Tinard (1996), os componentes da cadeia turística são quatro: transportes, alojamentos, alimentação e animação. De forma similar Lickorish e Jenkins (2000), embora reconheçam que não existe uma estrutura comum que represente a indústria do turismo em todos os países, também afirmam que há componentes do turismo claramente identificados, como o setor de acomodações (formais e informais), as 
agências de viagens e operadoras, os transportes, as compras e o artesanato. Nessa mesma linha de raciocínio, Andrade (2000) encara o turismo como atividades e serviços relacionados aos deslocamentos, transportes, alojamentos, alimentação, circulação de produtos típicos, atividades relacionadas aos movimentos culturais, visitas, lazer e entretenimento. Também, Cooper et alii (2001) enfatizam quatro componentes comuns na maioria das destinações turísticas: atrações, amenidades (hospedagem, alimentação, entretenimento, comércio e serviços), acesso e serviços auxiliares.

Para Lickorish e Jenkins (2000), à medida que o turismo se desenvolve ocorrem variações e aparecimento de tipos de serviços mais apropriados e em maior número que refletem também o tipo de turista que frequenta o local. Para suportar tal desenvolvimento há, ainda, uma abundância de outros serviços como bancos, aluguéis de veículos, compras e atrações culturais. Para esses autores, há dois elementos-chave no produto turístico que influenciam a escolha e o mercado turístico: (1) a combinação dos serviços necessários para a viagem com o transporte e a acomodação; (2) a satisfação realizada no destino escolhido. Cooper et alii (2001) esclarecem que as destinações precisam ser amálgamas no sentido de que é a qualidade e a uniformidade dos serviços prestados em cada componente do destino e neles como um todo que ocasiona a experiência turística completa vivida pelo turista. Também, destaca a característica da inseparabilidade da destinação do fenômeno turístico, pois o turismo é consumido onde é produzido, no destino turístico. Por fim, uma característica interessante dos destinos enfatizada é a da utilização múltipla das amenidades que podem servir aos visitantes e aos residentes locais. Nessa mesma linha de raciocínio Cooper et alii (2001) afirmam que, enquanto os fatores motivacionais ou de impulso instigam e influenciam a demanda o destino turístico, seus atrativos, infraestrutura e superestrutura compõem o principal fator de atração desta demanda turística.

Como os recursos naturais e culturais e os eventos da localidade são fatores diferenciais de um destino. Optou-se por não utilizá-los, neste trabalho, pois tais elementos são carregados de peculiaridades para as quais seria necessário um estudo específico para determinados destinos turísticos, não possibilitando uma análise de destinos em geral, a qual se constitui no objeto desta pesquisa. Escolheu-se, então, junto a especialistas, uma combinação de elementos da 
oferta turística básica e algumas características gerais inerentes aos destinos, sendo estas existentes na maior parte dos destinos turísticos, embora com suas variações.

Logicamente, o destino turístico não pode ser estudado de forma isolada, pois a compreensão do fenômeno só pode ser mais bem entendida quando também se refere à demanda. Considerou-se, então, para este artigo, que a destinação turística, com suas características e adequação à atividade, constitui-se no mais importante fator para atrair os visitantes. Depreende-se, então, que a satisfação do turista por um destino não ocorre somente pelo contentamento por um hotel, pela facilidade de transporte ou qualquer outro atrativo tomado individualmente. Assim, o fenômeno de desenvolvimento turístico de um destino ocorre por um conjunto de fatores que configuram o sistema turístico como um todo. Santos e Campos (2003) interpretaram o todo que configura o modelo conceitual de turismo sustentável em três elementos essenciais: o lugar, a comunidade local e o visitante. E este artigo analisa as características gerais do lugar, sob o ponto de vista do visitante.

\subsection{Turistas e demanda turística do destino}

Os turistas são indivíduos que se trasladam a um ou mais locais diferentes de sua residência habitual por um período maior que 24 horas e menor que 180 dias, sem participar dos mercados de trabalho e capital dos locais visitados. O entorno habitual de uma pessoa consiste em certa área ao redor de seu lugar de residência mais todos aqueles lugares que o indivíduo visita frequentemente (ORGANIZAÇÃO MUNDIAL DO TURISMO, 2001).

O turista é um agente externo ao local e relevante ao desenvolvimento do turismo. É o turista quem "consome" os produtos e serviços turísticos desenvolvidos no município. Portanto, é por meio dele que parte do desenvolvimento do turismo se processa. As outras partes devemse aos empresários e aos trabalhadores do setor, ao poder público e à própria comunidade, ou seja o desenvolvimento sofre a influência de visitantes e visitados. "Quando a comunidade não é favorável ao desenvolvimento da atividade turística, ela não será uma boa anfitriã nem fará esforços para divulgar a localidade e, consequentemente, o turista terá provavelmente uma experiência pouco agradável" (ZECHNER; ALVES; SAMPAIO, 2008, p. 35). Ao passar por uma experiência não condizente com as expectativas o turista não retorna ao local, 
e, pior, comenta com seus conhecidos sobre o incidente gerando um marketing negativo para o destino turístico.

Desta forma, de acordo com Goeldner, Ritchie e McIntosh (2002, p. 265), "[...] a demanda por viagens para um destino específico será uma função da propensão de uma pessoa viajar e da resistência recíproca ao vínculo entre áreas de origem e destino”. Para eles, a propensão refere-se à pré-disposição de uma pessoa para viajar, a qual depende do perfil psicográfico do visitante (preferências e motivações). Por outro lado, a resistência relaciona-se à atratividade relativa aos destinos. A atratividade dos destinos é uma função de diversas variáveis dentre as quais eles destacam a distância econômica (tempo e custo da viagem), distância cultural, custos dos serviços, qualidade dos serviços, eficácia da propaganda e promoção e sazonalidade. Segundo os mesmos autores a demanda é influenciada e limitada pela oferta.

De acordo com Cooper et alii (2001), a demanda pode ser real ou efetiva (aqueles que de fato estão viajando), reprimida (aqueles que não estão viajando por alguma razão) e sem-demanda (aqueles que não desejam viajar ou não têm condições para fazê-lo).

Em geral, os turistas utilizam-se de transporte, algum tipo de hospedagem, estabelecimentos de alimentação e desfrutam de características do destino. E são estes elementos gerais que são analisados neste artigo.

Segundo Lemos (2010, p. 248), "Há de se ter em conta que nenhum destino se mantém no auge eternamente. Turismo também tem relação com modismos e inovações, como outros produtos", ponto de vista reforçado por Mota (2001, p. 82), quando diz que "a demanda turística é muito sensível às condições sociopoliticas e às mudanças de moda e status em viagens". Assim sendo, um destino turístico só ultrapassa o patamar de localidade com potencial turístico configurando-se em um produto turístico e mantendo-se como tal quando oferece produtos e serviços que tenham a capacidade de satisfazer a um ou a mais segmentos da demanda turística. Quando não o faz corre o risco de tornar-se vulnerável à concorrência, entrando na fase de declínio preconizada por Butler (1991).

Dentre o quesito de satisfação muitos aspectos podem ser estudados. Dentre eles uma questão ainda pouco enfocada no setor, mas que a cada dia vem tomando maior grau de importância 
na percepção dos turistas é o fator segurança. Affolter (2003) explica que cresce a consciência no tocante à segurança e bem-estar dos turistas. $\mathrm{O}$ autor coloca que certos riscos e perigos nas viagens não podem ser eliminados por completo, mas a tolerância e a disposição em aceitar erros e incidências estão diminuindo. Butler e Jones (2003) comentam que o comportamento humano não se baseia em riscos reais, mas na percepção de riscos. No entanto, enquanto " $O s$ turistas parecem preocupar-se mais com desastres, que, em termos de probabilidade, causarão menos efeitos. O setor parece não se preocupar, ou não quer parecer preocupado". (BUTLER; JONES, 2003, p. 318),

Além da segurança com o desenvolvimento do turismo com bases sustentáveis o convívio entre visitantes e visitados tem revelado laços mais estreitos. A população participa mais ativamente do desenvolvimento local e da atividade turística, não só no que se trata de empregos gerados para eles, mas como protagonistas do próprio processo. O que revela destinos mais bem preparados para receber ao visitante minimizando impactos negativos advindos da atividade turística.

\section{Metodologia}

A hipótese básica desta pesquisa é que as características reveladas como importantes aos turistas apresentam diferentes graus entre os diversos tipos de respondentes, que representam segmentos variados na demanda. Para validar essa hipótese realizou-se uma pesquisa do tipo survey quanto à estratégia de abordagem do problema; exploratória e descritiva quanto aos objetivos; quantitativa quanto aos procedimentos de análise de dados; cross-sectional quanto à temporalidade de observação; bibliográfica, de pesquisa de campo e não experimental quanto aos procedimentos técnicos de coleta de informação; primária quanto à fonte de dados; não probabilística e do tipo snowball quanto ao processo de amostragem.

A pesquisa é do tipo survey, por internet, estruturada e aplicada a um grande número de respondentes, pois a partir de um website elaborado, a coleta de dados foi automatizada e disponibilizada em um banco de dados especialmente desenvolvido para este fim (MALHOTRA, 2001, p. 179). É, inicialmente, exploratória, pois objetiva identificar que 
atributos são considerados relevantes, na percepção do turista brasileiro, para a escolha de um destino turístico. É descritiva, pois objetiva sistematizar e descrever os dados coletados por meio de procedimentos estatísticos. É quantitativa quanto aos procedimentos de análise, pois usa procedimentos estatísticos de análise do tipo teste de hipóteses; análise fatorial exploratória; validação de construtos; construção de escalas e modelagem de equações estruturais para realizar a análise fatorial confirmatória. É cross-sectional quanto à temporalidade, porquanto se limita a um período determinado de observação, isto é, de doze de agosto de 2008 a dois de setembro de 2008. É não probabilística em virtude de os primeiros respondentes terem sido selecionados por conveniência segundo banco de dados de e-mails disponíveis pelos autores (contatos acadêmicos, profissionais e pessoais) e, a partir disso, cada respondente foi estimulado a re-encaminhar o e-mail para seus contatos, que também o fizeram e assim por diante.

Para realizar esta pesquisa partiu-se de onze características principais: dez escolhidas a partir da experiência dos pesquisadores sobre elementos da oferta turística básica e características gerais inerentes aos destinos turísticos e uma surgida da análise das respostas ao pré-teste (o item 5, opções de compras). As onze variáveis, medidas por grau de importância numa escala de 1 a 10, selecionadas para esta pesquisa, foram:

1. deslocamento e formas de acesso para o destino;

2. sensação de segurança;

3. qualidade do aspecto visual do destino;

4. hospedagem;

5. opções de compras;

6. opções de lazer;

7. sensação de não estar sendo explorado;

8. empatia com os turistas;

9. opções gastronômicas; 
10. disponibilidade de pacotes extras;

11. disponibilidade de informações turísticas e transporte no destino.

Após a análise do pré-teste, o questionário foi readequado e disponibilizado em website no período doze de agosto a dois de setembro de 2008 e foi respondido por 471 internautas de diversos estados brasileiros gerando 468 respostas válidas. Os dados foram tabulados em uma planilha XLS para posterior análise no SPSS e no AMOS. Uma cópia do questionário pode ser encontrada em http://pesquisamarcas.com/Turismo/.

\section{Apresentação e Análise dos Resultados}

A análise dos dados obedeceu à seguinte sequência:

1. sistematização dos dados, teste de normalidade dos dados ou distribuição mais aderente;

2. identificação, por meio de análise fatorial exploratória, da estrutura subjacente investigando a formação construtos que possam melhorar o entendimento do fenômeno;

3. verificação da validade interna de cada um dos construtos obtidos e depuração de cada um deles;

4. teste da validade do modelo fatorial encontrado utilizando-se de ferramentas de modelagem de equações estruturais e análise fatorial confirmatória.

\subsection{Caracterização da amostra}

Os respondentes, de ambos os sexos, deste projeto de pesquisa podem ser caracterizados, em sua maioria, como pessoas acima de 30 anos com renda familiar superior a $\mathrm{R} \$ 3.000,00$ (três mil reais). As Tabelas 4.1, 4.2 e 4.3 caracterizam a amostra segundo gênero, idade e renda familiar. A renda familiar foi inferida a partir do Critério Brasil da ABEP (a Associação 
Brasileira das Empresas de Pesquisa - ABEP - desenvolveu um critério de classificação socioeconômica chamado de Critério Brasil, o qual permite inferir o potencial de consumo de um indivíduo por uma análise de suas posses e hábitos de consumo, sem questionar diretamente sua faixa de renda) e a classificação de faixa etária foi discricionariamente atribuída pelos pesquisadores a partir de uma pré-análise da amostra.

Tabela 4.1: Distribuição da amostra segundo gênero e faixa etária

\begin{tabular}{|crrr|}
\hline \multirow{2}{*}{ Faixa Etária } & \multicolumn{2}{c}{ Gênero } & Total \\
\cline { 2 - 3 } & Masculino & Feminino & 61 \\
\hline Até 24 anos (inclusive) & 20 & 41 & 150 \\
De 25 a 34 anos & 59 & 91 & 131 \\
De 35 a 44 anos & 66 & 65 & 111 \\
De 45 a 59 anos & 49 & 62 & 15 \\
60 anos ou mais & 11 & 4 & 468 \\
\hline & 205 & 263 & \\
\hline
\end{tabular}

Tabela 4.2: Distribuição da amostra segundo gênero e renda familiar

\begin{tabular}{|rrrrr|}
\hline Faixa de Renda Familiar & \multicolumn{3}{c}{ Gênero } & Total \\
\cline { 2 - 3 } (em R\$) & 927 & 9 & 16 & 25 \\
& Masculino & Feminino & 50 \\
927,01 a $1.669,00$ & 24 & 26 & 75 \\
$1.669,01$ a $2.804,00$ & 27 & 48 & 93 \\
$2.804,01$ a $4.648,00$ & 33 & 60 & 97 \\
$4.648,01$ a $7.793,00$ & 47 & 50 & 128 \\
$7.793,00$ & 65 & 63 & 468 \\
\hline & 205 & 263 & \\
\hline
\end{tabular}

Tabela 4.3: Distribuição da amostra segundo faixa etária e renda familiar

\begin{tabular}{|rrrrrrr}
\hline $\begin{array}{r}\text { Faixa de Renda Familiar } \\
\text { (em RS) }\end{array}$ & \multicolumn{7}{c}{ Faixa Etária (em anos) } & Total \\
\cline { 2 - 7 } & Até 24 anos & 25 a 34 & 35 a 44 & 45 a 59 & $>60$ & 0 \\
\hline Até 927 & 12 & 6 & 4 & 3 & 25 \\
927,01 a 1.669,00 & 13 & 17 & 13 & 6 & 1 & 50 \\
$1.669,01$ a 2.804,00 & 18 & 28 & 15 & 14 & 0 & 75 \\
$2.804,01$ a 4.648,00 & 7 & 35 & 27 & 22 & 2 & 93 \\
$4.648,01$ a 7.793,00 & 8 & 29 & 35 & 21 & 4 & 97 \\
$>7793$ & 3 & 35 & 37 & 45 & 111 & 128 \\
\hline
\end{tabular}




\subsection{Estatística descritiva}

Inicialmente buscou-se identificar, por meio de frequência simples, qual era o atributo considerado mais relevante. A Tabela 4.4 sistematiza os resultados encontrados. Observa-se então que os atributos associados à segurança, aspecto visual do destino e formas de acesso se destacam. Uma característica comum a esses três atributos é que eles são, em grande parte, responsabilidades do poder público. Assim, reforça-se mais ainda a necessidade de gestão pública comprometida com o desenvolvimento local quando se trata de destinos turísticos. Outra informação importante advinda da pesquisa é que os cinco primeiros atributos respondem por cerca de $80 \%$ do que é considerado relevante para a escolha de destinos turísticos.

Tabela 4.4: Importância dos atributos na escolha de destinos turísticos

\begin{tabular}{|clrrr|}
\hline & & \multicolumn{3}{c|}{ Frequencia } \\
\hline \multirow{2}{*}{ Importância } & Atributos & Absoluta & $\begin{array}{r}\text { Relativa } \\
\text { Simples }\end{array}$ & $\begin{array}{r}\text { Relativa } \\
\text { Acumulada }\end{array}$ \\
\hline $1^{0}$ & Sensação de segurança & 109 & 23,29 & 23,29 \\
$2^{\circ}$ & Qualidade do aspecto visual do destino & 98 & 20,94 & 44,23 \\
$3^{\circ}$ & Deslocamento e formas de acesso para o destino & 71 & 15,17 & 59,40 \\
$4^{0}$ & Sensação de não estar sendo explorado & 52 & 11,11 & 70,51 \\
$5^{\circ}$ & Opções de lazer & 49 & 10,47 & 80,98 \\
$6^{0}$ & Disponibilidade de informações turísticas e transporte & 41 & 8,76 & 89,74 \\
$7^{0}$ & Hospedagem & 25 & 5,34 & 95,09 \\
$8^{0}$ & Empatia com os turistas & 16 & 3,42 & 98,50 \\
$9^{\circ}$ & Disponibilidade de pacotes extras & 4 & 0,85 & 99,36 \\
$10^{\circ}$ & Opções gastronômicas & 2 & 0,43 & 99,79 \\
$11^{0}$ & Opções de compras & 1 & 0,21 & 100,00 \\
\hline \hline
\end{tabular}

Ao utilizar a média dos valores das respostas como indicador de importância do atributo nenhuma mudança substantiva foi evidenciada entre os quatro primeiros atributos considerados mais relevantes. Com o critério de notas há um deslocamento do atributo hospedagem que ocupava a $7^{\mathrm{a}}$ posição e foi alçado para $5^{\mathrm{a}}$ posição, e do atributo opções de lazer que ocupava a $5^{\mathrm{a}}$ posição e foi deslocado para a $8^{\mathrm{a}}$ posição na segunda análise. Apesar disso, dos cinco atributos considerados mais relevantes na escolha individual, quatro deles também permanecem como atributos com as melhores notas. Quando tomados individualmente, os atributos sensação de segurança, qualidade do aspecto visual do destino e 
formas de acesso, independente do critério de seleção, permanecem como relevantes e são atributos, em grande parte, dependentes da qualidade da gestão da coisa pública.

Tabela 4.5. Importância dos atributos, pelo critério de notas, na escolha de destinos turísticos

\begin{tabular}{|clccc|}
\hline \multirow{2}{*}{ Importância } & Atributos & $\begin{array}{c}\mathrm{N}^{\text {o de }} \\
\text { observaçoes }\end{array}$ & Média & $\begin{array}{c}\text { Desvio } \\
\text { Padrão }\end{array}$ \\
\hline $1^{\circ}$ & Sensação de segurança & 463 & 9,01 & 1,67 \\
$2^{\circ}$ & Qualidade do aspecto visual do destino & 458 & 8,94 & 1,55 \\
$3^{\circ}$ & Sensação de não estar sendo explorado & 466 & 8,92 & 1,64 \\
$4^{\circ}$ & Deslocamento e formas de acesso para o destino & 463 & 8,86 & 1,70 \\
$5^{\circ}$ & Hospedagem & 465 & 8,80 & 1,43 \\
$6^{\circ}$ & Empatia com os turistas & 462 & 8,75 & 1,64 \\
$7^{0}$ & Opções gastronômicas & 466 & 8,65 & 1,52 \\
$8^{\circ}$ & Opções de lazer & 462 & 8,60 & 1,60 \\
$9^{\circ}$ & Disponibilidade de informações turísticas e transporte & 464 & 8,59 & 1,65 \\
$10^{\circ}$ & Disponibilidade de pacotes extras & 461 & 7,27 & 2,23 \\
$11^{\circ}$ & Opções de compras & 464 & 6,90 & 2,22 \\
\hline
\end{tabular}

Observa-se também que os atributos Disponibilidade de pacotes extras e Opções de compras apresentaram as menores médias e aumento expressivo do desvio-padrão. Isto indica uma variação maior na percepção dos respondentes com respeito à importância de cada um desses atributos. Análises adicionais não evidenciaram nenhuma associação entre esses atributos com qualquer uma das variáveis caracterizadoras do respondente observadas tais como gênero, idade e classificação econômica pelas faixas de renda do critério Brasil da ABEP.

\subsection{Caracterização da distribuição dos dados}

Foram utilizados os testes de Kolmogorov-Smirnov (teste KS) e Shapiro-Wilk para testar a hipótese da normalidade dos dados. Nesses testes os desvios da normalidade são constatados quando os valores da probabilidade associada a eles forem menores que 0,05 conforme pode ser observado na Tabela 4.6. 
Tabela 4.6 - Testes para a hipótese da normalidade dos dados

\begin{tabular}{|lrrr|rrr|}
\hline \multirow{2}{*}{ tributos } & \multicolumn{3}{c|}{ Kolmogorov-Smirnov(a) } & \multicolumn{3}{c|}{ Shapiro-Wilk } \\
& Statistic & df & Sig. & Statistic & \multicolumn{1}{c|}{ df } & Sig. \\
\hline Deslocamento e formas de acesso para o destino & 0,287 & 446 & 0,00 & 0,704 & 446 & 0,00 \\
Sensação de segurança & 0,311 & 446 & 0,00 & 0,646 & 446 & 0,00 \\
Qualidade do aspecto visual do destino & 0,268 & 446 & 0,00 & 0,708 & 446 & 0,00 \\
Hospedagem & 0,245 & 446 & 0,00 & 0,801 & 446 & 0,00 \\
Opções de compras & 0,152 & 446 & 0,00 & 0,937 & 446 & 0,00 \\
Opções de lazer & 0,200 & 446 & 0,00 & 0,818 & 446 & 0,00 \\
Sensação de não estar sendo explorado & 0,263 & 446 & 0,00 & 0,697 & 446 & 0,00 \\
Empatia com os turistas & 0,234 & 446 & 0,00 & 0,764 & 446 & 0,00 \\
Opções gastronômicas & 0,207 & 446 & 0,00 & 0,816 & 446 & 0,00 \\
Disponibilidade de pacotes extras & 0,185 & 446 & 0,00 & 0,91 & 446 & 0,00 \\
Disponibilidade de informações turísticas e transporte & 0,199 & 446 & 0,00 & 0,792 & 446 & 0,00 \\
\hline a Lilliefors Significance Correction & & & & & & \\
\hline
\end{tabular}

Os testes de normalidade foram significantes para todas as variáveis, ou seja, todas as variáveis apresentam significativos desvios da normalidade, o que implica cuidados adicionais na interpretação dos resultados das análises que se baseiam em correlação, como a análise fatorial e a regressão. Também é importante ressaltar que, conforme Mardia (1974), o teste de desvios da normalidade $\mathrm{T}^{2}$ de Hotelling é mais sensível à assimetria (skewness) do que ao achatamento (kurtosis). Ainda cumpre observar que desvios da normalidade, na área das Ciências Sociais, são relativamente comuns, e que isso não inviabiliza a utilização de técnicas paramétricas de análise, como a análise fatorial ou equações estruturais, havendo a recomendação na literatura de que se aumente o tamanho das amostras para que os resultados possam ser observados à luz do Teorema do Limite Central e sejam usadas técnicas de observação de intervalos de confiança corrigidos, como é o caso do procedimento de bootstrap no software AMOS, usado para a análise fatorial confirmatória. Segundo Hair Jr. et alii (1998, p. 98, tradução dos autores):

Com respeito à questão do tamanho da amostra o pesquisador normalmente não fará uma análise fatorial de uma amostra com menos de 50 observações e, preferivelmente, o tamanho da amostra deve ser de 100 ou maior. Como regra geral o mínimo é ter pelo menos 5 vezes o número de variáveis a serem analisadas como número de observações e o tamanho mais aceitável teria uma razão de 10 para 1 . Alguns pesquisadores ainda propõem o mínimo de 20 casos para cada variável. 
E, ainda, "Em casos de desvios da normalidade o parâmetro geralmente aceito é uma razão de 15 para 1". (HAIR JR. et alii, 1998, p. 605, tradução dos autores). Adicionalmente, segundo Kline (2005, p. 15, tradução dos autores), “Tamanhos de amostra menores que 100 casos são considerados pequenos, entre 100 e 200 médios e maiores que 200 casos podem ser considerados grandes, robustas por conta do Teorema do Limite Central'. Segundo Garson (2008, tradução dos autores), "Na literatura, os tamanhos de amostra normalmente variam de 200 a 400 para modelos com 10 a 15 indicadores"; por fim, pode-se citar Stevens (2002, p. 395, tradução dos autores), "O tamanho da amostra deve ser de pelo menos trezentos", condições estas totalmente atendidas pela amostra em análise.

A referência para distribuições simétricas é que a estatística assuma valor próximo de zero. Valores negativos da estatística caracterizam assimetria negativa. Na Tabela 4.7 observa-se que todas as variáveis apresentaram assimetria negativa caracterizando maior quantidade de respondentes escolhendo o extremo superior da escala. Isso denota a relevância das variáveis selecionadas para o presente estudo. Esse efeito ocorre em menor proporção nas variáveis 5 (Opções de Compra) e 10 (Disponibilidade de Pacotes Extras). Ainda, nota-se que as médias dessas duas variáveis (6,90 e 7,27 respectivamente) foram menores que as demais (todas acima de 8,50), corroborando o efeito descrito.

A referência para o achatamento (curtose) é que a estatística assuma valor zero, isto é, a estatística apresentada já é o excesso de curtose. Na Tabela 4.7, observam-se valores bem superiores a zero para todas as variáveis, exceto para as variáveis Opções de compras e Disponibilidade de pacotes extras. Isso reforça a caracterização de uma distribuição pontiaguda (leptocúrtica) com a maioria dos valores concentrados no extremo superior da escala. 
Tabela 4.7 - Estatísticas Descritivas

\begin{tabular}{|c|c|c|c|c|c|c|c|c|}
\hline Variáveis & Atributos & $\mathrm{N}$ & Mínimo & Máximo & Média & $\begin{array}{l}\text { Desvio } \\
\text { Padrão } \\
\end{array}$ & Assimetria & Curtose \\
\hline 1 & Deslocamento e formas de acesso para o destino & 464 & 1 & 10 & 8,86 & 1,695 & $-2,044$ & 4,871 \\
\hline 2 & Sensação de segurança & 464 & 1 & 10 & 9,01 & 1,669 & $-2,382$ & 6,303 \\
\hline 3 & Qualidade do aspecto visual do destino & 459 & 1 & 10 & 8,93 & 1,551 & $-2,111$ & 5,496 \\
\hline 4 & Hospedagem & 466 & 2 & 10 & 8,80 & 1,432 & $-1,529$ & 3,165 \\
\hline 5 & Opções de compras & 465 & 1 & 10 & 6,90 & 2,219 & $-0,691$ & 0,073 \\
\hline 6 & Opções de lazer & 463 & 1 & 10 & 8,60 & 1,595 & $-1,519$ & 2,989 \\
\hline 7 & Sensação de não estar sendo explorado & 467 & 1 & 10 & 8,92 & 1,636 & $-2,209$ & 5,643 \\
\hline 8 & Empatia com os turistas & 463 & 1 & 10 & 8,75 & 1,640 & $-1,824$ & 3,887 \\
\hline 9 & Opções gastronômicas & 467 & 1 & 10 & 8,64 & 1,520 & $-1,523$ & 3,158 \\
\hline 10 & Disponibilidade de pacotes extras & 462 & 1 & 10 & 7,27 & 2,231 & $-0,865$ & 0,325 \\
\hline 11 & Disponibilidade de informações turísticas e transporte & 465 & 1 & 10 & 8,57 & 1,676 & $-1,692$ & 3,684 \\
\hline
\end{tabular}

$\mathrm{O}$ teste de diferença de médias (teste t) aplicado à amostra segmentada por gênero apresentou os seguintes resultados:

1) A percepção da importância do atributo sensação de não estar sendo explorado apresentou maior dispersão entre o segmento masculino (Rejeição da hipótese nula de homogeneidade das variâncias pelo Teste de Levene), isto é, além da percepção da importância do atributo variar segundo o gênero, os respondentes do sexo masculino têm maior divergência entre si quanto a sua importância.

2) A hipótese de homogeneidade das médias amostrais foi rejeitada para as variáveis 4 (Hospedagem) e 11 (Disponibilidade de informações turísticas e transporte) com os maiores valores apresentados pelo segmento feminino da amostra.

Um teste ANOVA para a hipótese de não divergência de percepção entre os respondentes de diferentes faixas de renda quanto à relevância dos atributos, encontrou evidências estatísticas suficientes de rejeição apenas para os atributos sensação de segurança e disponibilidade de pacotes extras. Em síntese, turistas de diferentes faixas de renda têm percepção diferenciada quanto à relevância destes dois atributos como elemento influenciador da decisão de escolha de destinos turísticos. Turistas com maior faixa de renda tendem a valorizar mais o atributo de segurança, enquanto os de menor faixa de renda a valorizar mais a disponibilidade de pacotes extras. 


\title{
4.4. Análise fatorial exploratória
}

A análise fatorial exploratória (ou EFA, de Exploratory Factor Analysis) revela a estrutura subjacente aos dados observados. Qualifica-se como exploratória porque não se faz nenhum pressuposto a respeito de como as variáveis observadas se associam em fatores, ou, como foi descrito por Garson (2008), “o pressuposto a priori do pesquisador é de que qualquer indicador pode ser associado com qualquer fator".

A análise por componentes principais é uma das modalidades disponíveis de análise fatorial, sendo a mais amplamente usada, buscando a combinação linear das variáveis tais que a variância extraída seja máxima, ou seja, busca-se o conjunto de fatores que maximiza a explicação de variância do sistema (GARSON, 2008; HAIR et alii, 1998; STEVENS, 2001).

Como explicitado por Hair et alii (1998, p. 91):

\begin{abstract}
A análise fatorial pode ter um papel fundamental na aplicação de outras técnicas multivariadas. A vantagem principal da análise fatorial é sua habilidade em acomodar múltiplas variáveis na tentativa de compreender suas complexas interrelações, o que não seria possível com métodos univariados ou bivariados. [...] grupos de variáveis podem estar inter-relacionados de tal forma que sejam representativos de um conceito mais amplo e geral.
\end{abstract}

Ainda segundo Hair et alii (1998), os pressupostos para a análise fatorial são mais conceituais que estatísticos. Os desvios da normalidade, a heteroscedasticidade e a ausência de linearidade simplesmente atuam no sentido de diminuírem a correlação observada entre variáveis. $\mathrm{Na}$ verdade algum grau de colinearidade entre as variáveis é desejável, para que estas possam compartilhar alguma variância e se agrupar em fatores.

Com respeito ao número de fatores extraídos, o critério mais usual é o critério de raízes latentes (latent root criterion) ou dos autovalores (eigenvalues). Com relação à adequação dos dados à análise fatorial, são utilizados, basicamente, três critérios:

1) Teste de esfericidade de Bartlett: é um teste qui-quadrado que verifica a hipótese nula de que a matriz de correlação seja uma matriz identidade, ou seja, que as variáveis não 
sejam significativamente correlacionadas. $O$ teste precisa ser significante $(p<0,05)$ para que se possa prosseguir com a análise fatorial.

2) Teste KMO ou Kaiser-Meyer-Olkin: é uma medida de adequação amostral (MSA Measure of Sampling Adequacy) global dos dados, indicando a adequação dos mesmos à análise fatorial ou não. Normalmente, usam-se os valores e indicativos conforme o Quadro 4.1.

3) MSA individuais: as medidas de adequação amostral de cada uma das variáveis podem ser observadas na diagonal da matriz anti-imagem de correlação. O Quadro 4.1 apresenta os critérios de adequação amostral nos quais variáveis com MSA inferior a 0,5 devem ser removidas da análise.

Quadro 4.1: Critérios de Análise do MAS

\begin{tabular}{|c|c|}
\hline MSA & Indicativo \\
\hline 0,80 ou superior & Meritório \\
\hline 0,70 a 0,80 & Mediano \\
\hline 0,60 a 0,70 & Medíocre \\
\hline 0,50 a 0,60 & Miserável \\
\hline 0,50 ou menor & Inaceitável \\
\hline
\end{tabular}

A análise fatorial por componentes principais apresentou os resultados como se vê nas tabelas 4.8 e 4.9 .

Tabela 4.8: Testes KMO e Bartlett

\begin{tabular}{|l|r|}
\hline Teste & Resultado \\
\hline Medida de adequação da amostra de Kaiser-Meyer-Olkin (KMO) & 0,893 \\
\hline Teste de esfericidade de Bartlett & \\
\hline Qui-quadrado aproximado & 1712,75 \\
\hline Graus de liberdade (df) & 55 \\
\hline Significância do teste & 0 \\
\hline
\end{tabular}




\section{TURISMO EM ANÁLISE}

Tabela 4.9: Autovalores e Variância Explicada para três fatores

\begin{tabular}{|c|c|c|c|c|c|c|c|c|c|}
\hline \multirow{2}{*}{ Componentes } & \multicolumn{3}{|c|}{ Autovalores Iniciais } & \multicolumn{3}{|c|}{ Somas dos Carregamentos Quadráticos Extraídos } & \multicolumn{3}{|c|}{ |Somas dos Carregamentos Quadráticos Rotacionados } \\
\hline & Total & \% de Variância & $\%$ Acumulado & Total & \% de Variância & $\%$ Acumulado & Total & \% de Variância & $\%$ Acumulado \\
\hline 1 & 4,793 & 43,577 & 43,577 & 4,793 & 43,577 & 43,577 & 2,536 & 23,051 & 23,051 \\
\hline 2 & 1,154 & 10,493 & 54,071 & 1,154 & 10,493 & 54,071 & 2,514 & 22,854 & 45,905 \\
\hline 3 & 0,898 & 8,162 & 62,233 & 0,898 & 8,162 & 62,233 & 1,796 & 16,328 & 62,233 \\
\hline 4 & 0,772 & 7,021 & 69,254 & & & & & & \\
\hline 5 & 0,639 & 5,809 & 75,063 & & & & & & \\
\hline 6 & 0,566 & 5,149 & 80,211 & & & & & & \\
\hline 7 & 0,534 & 4,852 & 85,064 & & & & & & \\
\hline 8 & 0,470 & 4,273 & 89,337 & & & & & & \\
\hline 9 & 0,432 & 3,926 & 93,263 & & & & & & \\
\hline 10 & 0,404 & 3,677 & 96,940 & & & & & & \\
\hline 11 & 0,337 & 3,060 & 100,000 & & & & & & \\
\hline Método de Ex & ào: An & de Compone & Principais & & & & & & \\
\hline
\end{tabular}

O KMO situou-se na região de valor considerado bom (marginalmente tendendo a muito bom, que seria superior a 0,9). O teste de Bartlett, como esperado, acusou significância no Quiquadrado, indicando rejeição à hipótese nula da matriz de correlação ser a matriz identidade.

O autovalor total (ou traço) é o somatório dos autovalores da matriz dos componentes principais, que é igual ao número de variáveis analisadas, já que cada variável contribui com um valor unitário para o traço. Assim sendo, o critério das raízes latentes especifica que devem ser considerados os fatores que apresentem autovalores maiores que a unidade, ou seja, cuja contribuição seja maior que a de uma variável individual (HAIR et alii, 1998, p. 103). Todavia, conforme Garson (2008), o critério de Kaiser, ou da raiz latente, que seleciona os fatores associados a autovalores superiores à unidade, pode ser demasiadamente exagerado no corte de fatores, principalmente se for o único critério de retenção. Assim sendo, e na tentativa de buscar uma explicação de variância do sistema superior a $60 \%$, optou-se pela utilização de três fatores, conforme a tabela 4.9 , explicando assim $62,23 \%$ da variância total do sistema.

A Tabela 4.10 mostra a Matriz dos Componentes Rotacionados para três fatores. O primeiro fator é composto pelas variáveis $11,7,8$ e 9; o segundo fator é composto pelas variáveis 1,3 , 2 e 6 e terceiro fator é composto pelas variáveis 5,10 e 4 . 
Tabela 4.10: Matriz dos Componentes Rotacionados para três fatores

\begin{tabular}{|clrc|}
\hline Variáveis & Atributos & \multicolumn{2}{c|}{ Componentes } \\
\cline { 3 - 4 } & & 1 & 2 \\
\hline 11 & Disponibilidade de informações turísticas e transporte & 0,780 & \\
7 & Sensação de não estar sendo explorado & 0,710 & \\
8 & Empatia com os turistas & 0,684 & \\
9 & Opções gastronômicas & 0,579 & \\
\hline 1 & Deslocamento e formas acesso para o destino & 0,723 \\
3 & Qualidade do aspecto visual do destino & 0,709 \\
2 & Sensação de segurança & 0,696 & \\
6 & Opções de lazer & & 0,610 \\
\hline 5 & Opções de compras & & 0,877 \\
10 & Disponibilidade de pacotes extras & & 0,650 \\
4 & Hospedagem & & 0,458 \\
\hline
\end{tabular}

Método de Extração: Análise de Componentes Principais

Método de Rotação: Varimax com normalização de Kaiser

Como os atributos Disponibilidade de pacotes extras e Opções de compras apresentaram comportamento bastante diferente das demais, com elevada dispersão, tentou-se associar esse comportamento a alguma das variáveis caracterizadoras do respondente (gênero, idade e classificação econômica pelas faixas de renda do critério Brasil da ABEP), mas não foi possível determinar uma associação com qualquer uma delas. Como alternativa, tentou-se extrair essas variáveis da análise fatorial, porém os resultados obtidos não foram significativamente melhores que os originais. Assim, optou-se por mantê-las em todas as análises, mas é recomendável que, em futuras pesquisas, sejam buscados os fatores que auxiliem na explicação dessa variedade de comportamento por parte dessas variáveis.

\subsection{Escalas e o Alfa de Cronbach}

A associação das variáveis observadas em fatores conduz à hipótese de que essas variáveis possam combinar-se de modo a formarem uma escala de medida. Uma escala precisa ter validade interna de construto (também chamada de consistência ou confiabilidade), e a medida dessa confiabilidade é dada por um índice chamado de Alfa de Cronbach. Quanto mais próximo seu valor estiver da unidade, melhor a consistência interna do construto; o nível crítico para essa medida é de 0,6 (MALHOTRA, 1999, p. 265), ou seja, se o valor encontrado para o Alfa de Cronbach for inferior a esse nível, a escala é considerada sem validade interna, 
portanto as variáveis não formam um construto. A análise das escalas apresentou os resultados conforme o Quadro 4.4.

Quadro 4.4: Valores do Alfa de Cronbach dos Fatores

\begin{tabular}{|c|c|}
\hline Fator & Alfa de Cronbach \\
\hline F1 & 0,806 \\
\hline F2 & 0,752 \\
\hline F3 & 0,672 \\
\hline
\end{tabular}

Observa-se que todos os fatores apresentaram valores de confiabilidade acima do valor crítico, evidenciando a validade dos fatores formados. Claramente, observa-se que o primeiro fator é o que apresenta maior validade interna, ou seja, as variáveis que o compõem têm uma estrutura de covariância bastante forte, e que a qualidade dessa consistência vai diminuindo para o fator 2 e ainda mais para o fator 3. Ainda assim, apesar desse decaimento, pode-se inferir que as escalas possuem validade interna e que as variáveis podem ser combinadas dessa forma para que se obtenha uma unidade de medida de cada uma das dimensões representadas pela estrutura fatorial.

\subsection{Análise fatorial confirmatória por meio de análise de estruturas de covariância}

A análise fatorial confirmatória (ou CFA, de Confirmatory Factor Analysis) é uma técnica que emergiu da teoria de equações estruturais e que guarda profunda similaridade de funcionamento com ela, baseando-se também nas análises das estruturas de covariância determinadas a partir dos dados amostrais coletados.

Em contraposição à análise fatorial exploratória, em que não há suposições a priori sobre a estrutura fatorial ou dimensional das variáveis estudadas, na CFA é adotada uma estratégia de elaborar um modelo (oriundo de uma EFA ou de revisões teórico-empíricas) e validá-lo confrontando-o com parâmetros de ajuste previamente estabelecidos.

O modelo foi adicionalmente testado no AMOS por meio da técnica de bootstrap, na qual é feita uma reamostragem a partir da amostra original e que, tradicionalmente, é utilizada para a 
compensação dos efeitos nocivos introduzidos pela não normalidade dos dados observados (BYRNE, 2001).

A modelagem estrutural é a técnica que toma as variáveis observadas (ou manifestas, na nomenclatura própria da técnica) e as agrupa em fatores (ou variáveis latentes); essas variáveis latentes, de acordo com uma teoria ou hipótese pré-concebida, são inter-relacionadas e formam um sistema de equações que é resolvido de forma a minimizar discrepâncias entre os valores observados e os valores calculados pelo modelo (no caso, pelo método da máxima verossimilhança). A técnica trabalha com estruturas de covariância, ou seja, ao ser montado um modelo estrutural, agrupando os dados em fatores e deixando os fatores se correlacionarem, tenta-se reproduzir neste modelo a matriz de covariância apresentada pelos dados amostrais analisados. As medidas de ajustamento do modelo, ou seja, o quanto ele é bom ou ruim, baseiam-se nas diferenças encontradas entre a matriz de covariância observada e a matriz de covariância calculada.

Cumpre observar que essa modelagem é uma técnica que exige uma série de pressupostos e de fundamentações teóricas, pois o modelo de inter-relação entre as variáveis latentes, bem como a composição destas por meio do agrupamento de variáveis manifestas é um a priori do modelo, ou seja, ela se presta a uma análise fatorial confirmatória de um modelo definido por uma análise fatorial exploratória.

O software AMOS (Analysis of Moment Structures) utiliza, para a análise estrutural, três modelos: um modelo nulo, ou de independência, em que as variáveis são deixadas variar livremente, ou seja, assume-se que não há relação entre elas, sendo que o número de graus de liberdade é máximo; um modelo saturado, no qual não há graus de liberdade, ou seja, todas as variáveis encontram-se ligadas a outras e o modelo em análise. O AMOS apresenta os índices de ajuste para cada um dos modelos, e o ajuste é determinado exatamente o por quão bom seja cada índice do modelo analisado em relação aos modelos independente e saturado.

O uso do AMOS para modelar o fenômeno foi baseado no modelo indicado na Figura 1. 


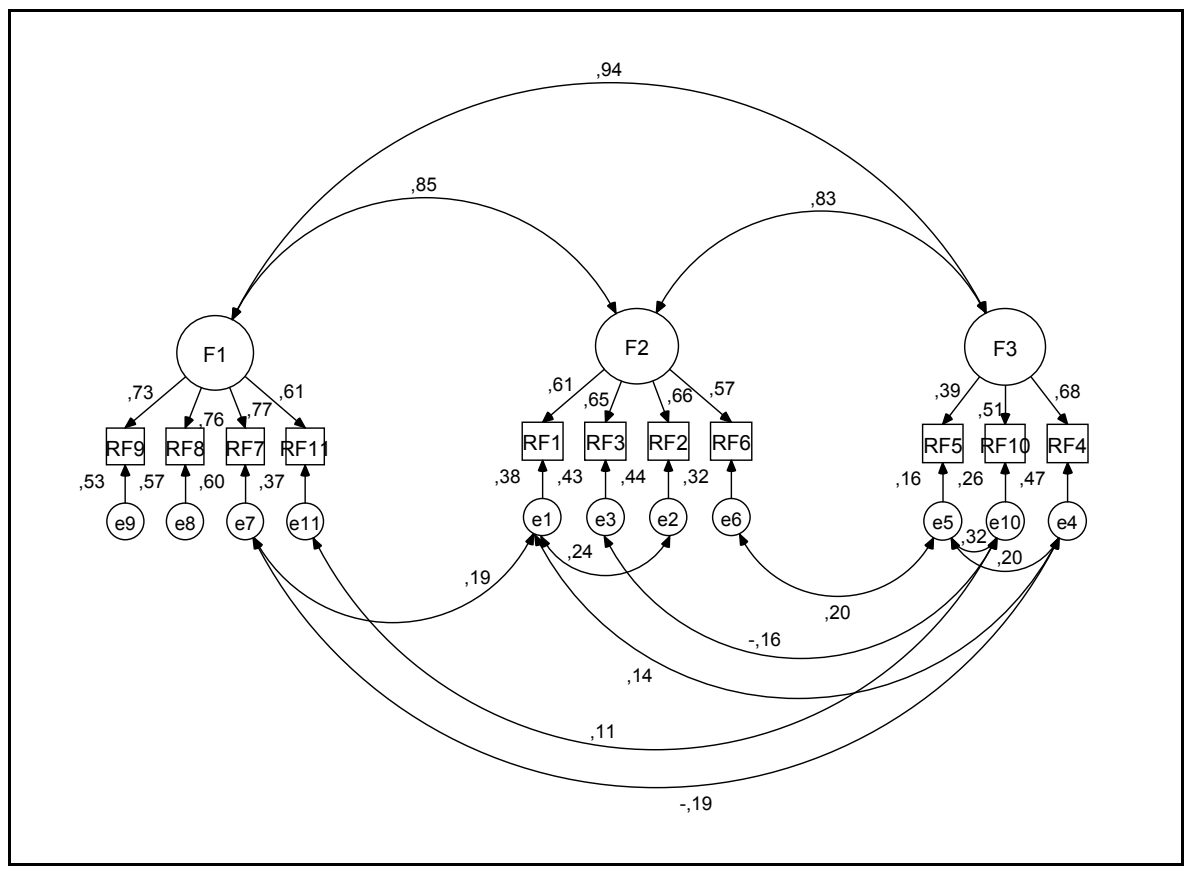

Figura 1: Modelo de Equação Estrutural com três Fatores

A Análise Fatorial Confirmatória sobre o modelo estrutural confirmou os fatores, porém com ajuste pobre do modelo obtido ao serem forçadas as correlações entre os construtos para o valor zero (ortogonalidade fatorial). Tal comportamento rejeita a ortogonalidade dos fatores, o que ensejou a verificação com a livre correlação fatorial, com o que se obteve os valores como segue:

1. $\operatorname{correl}(\mathrm{F} 1, \mathrm{~F} 2)=0,846$

2. $\operatorname{correl}(\mathrm{F} 1, \mathrm{~F} 3)=0,944$

3. $\operatorname{correl}(\mathrm{F} 2, \mathrm{~F} 3)=0,826$

Assim, a Análise Fatorial Confirmatória revela que a estrutura fatorial não é ortogonal, o que exige maior cuidado na interpretação dos fatores, ou seja, embora sejam fatores diferentes (conforme indicado na Análise Fatorial Exploratória) a relação entre eles é forte.

Os índices de ajustamento do modelo ficaram bastante bons, apresentando-se como segue: 
1) $\mathrm{O} R M R=0,075$ está acima do máximo recomendado $(0,05)$, porém abaixo do máximo tolerável indicado na literatura, que é de 0,08 , todavia tanto o GFI $=0,983$ como o AGFI $=$ 0,965 , estão com valores bons, significativamente acima de 0,9 conforme recomenda a literatura.

2) Índice de ajustamento geral: Qui-quadrado $=43,020$ para 32 graus de liberdade, dando o $\chi^{2} / \mathrm{GL}=1,344$, apresentando a probabilidade $\mathrm{p}$ associada igual a 0,092 indicando que não é possível rejeitar a hipótese nula de que a matriz de covariância estimada pelo modelo seja igual à matriz de covariância calculada a partir dos dados apresentados (o valor crítico para esta observação é de 0,05 , ou seja, valores abaixo disso indicam a rejeição da hipótese nula).

3) $\mathrm{NFI}=0,975 ; \mathrm{TLI}(\mathrm{NNFI})=0,989$ e CFI $=0,993$ satisfazem o critério de apresentarem valores maiores que 0,9 e desejavelmente acima de 0,95 .

4) $\operatorname{RMSEA}=0,028$ com intervalo de confiança de $90 \%=(0,000,0,048)$ garantindo que o erro médio quadrático total do modelo está inferior a 0,05 , que é o valor máximo recomendado pela literatura especializada, fato atestado pelo PCLOSE $=0,969$.

5) $\mathrm{AIC}=111,020$ (para 132,000 do modelo saturado) e $\mathrm{BCC}=112.908$ (para 135,667 do modelo saturado). Tanto o AIC, como o BCC, que são critérios de qualidade da forma "quanto menor, melhor", devem apresentar para o modelo analisado valores menores que para o modelo saturado, que é o modelo sem graus de liberdade.

\section{Conclusões}

Esta pesquisa teve como hipótese básica que os atributos revelados como relevantes, na percepção dos turistas brasileiros, para a decisão de escolha de um destino turístico, apresentam diferenças significativas entre os diversos tipos de respondentes segundo gênero, idade e classificação socioeconômica do Critério Brasil da ABEP. Buscava-se com isso encontrar alguma segmentação da demanda por destinos turísticos. Os testes estatísticos realizados no sentido de afirmar que não há diferença significativa na escolha dos atributos segundo o tipo de respondente não encontrou evidências estatísticas suficientes para sua rejeição. 
Dentre os onze atributos listados, os respondentes consideraram que os atributos associados à sensação de segurança, aspecto visual do destino e formas de acesso ao destino se destacam. Outra informação importante advinda da pesquisa é que estes três atributos mais os atributos de sensação de não estar sendo explorado e opções de lazer respondem por cerca de $80 \%$ do que é considerado relevante para a escolha de destinos turísticos. Assim sendo, ao promover a satisfação dos turistas com relação a esses itens, pode-se dizer que 80\% deles sentir-se-ão bem atendidos em suas expectativas. Indicadores de melhoria ou piora nestes aspectos podem ser úteis aos destinos turísticos que intencionem uma demanda doméstica do ponto de vista de seu planejamento e gestão para gerar maior atratividade para esta demanda. Uma característica comum aos três atributos principais é que eles são, em grande parte, responsabilidades do poder público reforçando, destarte, ainda mais a necessidade de gestão pública comprometida com o desenvolvimento local quando se trata de destinos turísticos.

Ao utilizar a média dos valores das respostas como proxy da relevância, o atributo sensação de segurança foi o mais bem pontuado $(9,01)$ com diferença não significativa para os demais atributos exceto para os atributos disponibilidade de pacotes extras $(7,27)$ e opções de compras $(6,90)$ que receberam as menores pontuações. Também aqui, independente do critério de seleção, os atributos selecionados, em grande parte, dependem da qualidade da gestão da coisa pública.

Da Análise Fatorial Exploratória para revelar a estrutura subjacente aos dados observados conclui-se que três fatores extraídos explicam $62,23 \%$ da variância total do sistema. $\mathrm{O}$ primeiro fator, responsável por $23,05 \%$ da variância extraída, é constituído pelos atributos disponibilidade de informações turísticas e transporte, sensação de não estar sendo explorado, empatia com os turistas e opções gastronômicas. O segundo fator é constituído pelos atributos deslocamento e formas de acesso ao destino turístico, qualidade do aspecto visual do destino turístico, sensação de segurança e opções de lazer, e responde por 22,85\% da variância do sistema. O terceiro fator, responsável por $16,33 \%$ da variância explicada, é constituído pelos atributos opções de compras, disponibilidade de pacotes extras e hospedagem.

A estrutura fatorial observada não foi totalmente compatível com os pressupostos teóricos examinados na fundamentação do trabalho, o que enseja um maior aprofundamento do tema e mais pesquisas para descrever mais adequadamente o fenômeno observado e suas disjunções 
com a teoria. Observa-se que a teoria analisada é fundamentada em autores europeus enquanto a pesquisa foi conduzida com respondentes brasileiros, o que pode ensejar que a percepção dos brasileiros quanto à importância e relevância dos aspectos turísticos seja diferente da dos europeus.

A análise fatorial confirmatória (CFA) revelou que os três fatores se correlacionam fortemente (F1 e F3 r=0,944; F1 e F2 r=0,846; F2 e F3 r=0,826), o que revela que a estrutura fatorial não é ortogonal, o que exige maior cuidado na interpretação dos fatores. Ou seja, embora sejam fatores diferentes a relação entre eles é forte.

Apesar de o presente estudo ter sido conduzido sobre uma amostra robusta e de tamanho adequado, sugere-se prosseguir esta investigação buscando a melhoria da caracterização da estrutura fatorial encontrada, de forma a ampliar os resultados do trabalho que, de toda forma, chegou a conclusões inéditas no contexto nacional e que contribuem para o entendimento da percepção dos turistas com relação aos atributos desejados dos destinos turísticos.

\section{Referências}

AFFOLTER, Daniel. 2003. O Mercado do Turismo: Novos Desafios. In: LOCKWOOD, Andrew; MEDLIK, S. (org.). Turismo e hospitalidade no século XXI. Barueri: Manole.

ANDRADE, José Vicente. 2000. Turismo: Fundamentos e Dimensões. São Paulo: Ática.

BENI, Mário Carlos. 2000. Análise Estrutural do Turismo. São Paulo: SENAC.

BOULLÓN, Roberto. 1985. C. Planificación del espacio turístico. México: Trillas.

BUTLER, Richard. 1991. The concept of a tourist area cycle of evolution: implications for management of resources. In: Canadian Geografer, v. 24, p.5-12.

BUTLER, Richard; JONES, P. 2003. Conclusões - Problemas, Desafios e Soluções. In: LOCKWOOD; MEDLIK (org.). Turismo e hospitalidade no século XXI. Barueri: Manole.

BYRNE, Barbara M. 2001. Structural Equation Modelling with AMOS: basic concepts, applications, and programming. New Jersey: Lawrence Erlbaum.

COOPER, Christopher P. et alii. 2001. Turismo: Princípios e Prática. 2 ed. Porto Alegre: Bookman.

DIAS, Reinaldo. 2005. Introdução ao Turismo. São Paulo: Atlas. 
GARSON, G. D. S/D. Factor Analysis. Disponível em: <http://faculty.chass.ncsu.edu/garson/ PA765/factor.htm> acesso em 11 dez. 2008.

GOELDNER, Charles R.; RITCHIE, J. R. Brent; MCINTOSH, Robert W. 2002. Turismo: Princípios, Práticas e Filosofias. 8 ed. Porto Alegre: Bookman.

HAIR JR., Joseph F; ANDERSON, Ralph E; TATHAM, Ronald L; BLACK, Willian. 1998. Multivariate Data Analysis. 5. ed. New Jersey: Prentice Hall.

KLINE, Rex B. 2005. Principles and Practice of Structural Equation Modeling. 2nd ed. New York: Guilford.

LEMOS, Iomara Scandelari. 2010. Proposta de Metodologia para Classificação de Destinos Turísticos Típicos Segundo os Princípios de Sustentabilidade por Meio de Análise Multicritério. 2010. Tese (Doutorado em Administração) - Programa de Pós-graduação em Administração/PUCPR, Curitiba.

LICKORISH, Leonard J.; JENKINS, Carson L. 2000. Introdução ao turismo. Rio de Janeiro: Campus.

MALHOTRA, Naresh K. 1999. Pesquisa de Marketing: uma orientação aplicada. 3 ed. Porto Alegre: Bookman.

MARDIA, K. V. 1970. Measures of multivariate skewness and kurtosis with applications. Biometrika. Oxford University Press, v.57, n.3, p. 519-530.

MOTA, Keila C. N. 2001. Marketing Turístico: promovendo uma atividade sazonal. São Paulo: Atlas.

ORGANIZAÇÃO MUNDIAL DO TURISMO. 2001. Introdução ao Turismo. São Paulo: Roca.

PLOG, Stanley. 2001. Why Destination Areas Rise and Fall Popularity. In: Cornell Hotel and Restaurant Administration Quarterly, vol. 42, n. 3, August.

SANTOS, Cristiane Alcântara de Jesus; CAMPOS, Antônio Carlos. 2003. Estratégias para o Desenvolvimento Sustentável do Turismo. In: CORIOLANO, L. N. M. T. Turismo Comunitário e Responsabilidade Social. Fortaleza: EDUECE, p 161-172.

STEVENS, James P. 2002. Applied Multivariate Statistics for the Social Sciences. Lawrence Erlbaum Associates.

TINARD, Yves. 1996. Turismo: Economía y gestión. Barcelona: Bosch.

ZECHNER, Talita C.; ALVES, Flávia K.; SAMPAIO, Carlos Alberto C. 2008. O Papel do Turismo no Arranjo Socioprodutivo de Base Comunitária da Micro-Bacia do Rio Sagrado. In: Dynamics revista técnico-científica. Blumenau: FURB, n. 14, vol. 1, jan.-mar.

\section{Recebido em: 14/04/2009}

Aprovado em: 03/05/2010 (1 ${ }^{\mathrm{a}}$ versão) $31 / 07 / 2010$ ( $2^{\mathrm{a}}$ versão) 